\title{
Etiology of neonatal seizures and maintenance therapy use: a 10-year retrospective study at Toulouse Children's hospital
}

\author{
E. Baudou ${ }^{1,3^{*}}$ D, C. Cances ${ }^{1}$, C. Dimeglio ${ }^{2}$ and C. Hachon Lecamus ${ }^{1}$
}

\begin{abstract}
Background: No guidelines exist concerning the maintenance antiepileptic drug to use after neonatal seizures. Practices vary from one hospital to another. The aim of this study was to investigate etiologies and to report on the use of maintenance antiepileptic therapy in our population of full-term neonates presenting neonatal seizures.

Methods: From January 2004 to October 2014, we retrospectively collected data from all full-term neonates with neonatal seizures admitted to the Children's Hospital of Toulouse, France.

Results: Two hundred and forty-three neonates were included (59\% males, 48\% electroencephalographic confirmation). The frequencies of etiologies of neonatal seizures were: hypoxic-ischemic encephalopathy (HIE) $(n=91 ; 37 \%)$, ischemic infarction $(n=36 ; 15 \%)$, intracranial hemorrhage $(n=29 ; 12 \%)$, intracranial infection $(n=19 ; 8 \%)$, metabolic or electrolyte disorders $(n=9 ; 3 \%)$, inborn errors of metabolism $(n=5 ; 2 \%)$, congenital malformations of the central nervous system $(n=11 ; 5 \%)$, epileptic syndromes $(n=27 ; 12 \%)$ and unknown $(n=16 ; 7 \%)$. A maintenance therapy was prescribed in 180 (72\%) newborns: valproic acid $(n=123)$, carbamazepine $(n=28)$, levetiracetam $(n=17)$, vigabatrin $(n=2)$, and phenobarbital $(n=4)$. In our cohort, the choice of antiepileptic drug depended mainly on etiology. The average duration of treatment was six months.
\end{abstract}

Conclusions: In our cohort, valproic acid was the most frequently prescribed maintenance antiepileptic therapy. However, the arrival on the market of new antiepileptic drugs and a better understanding of the physiopathology of genetic encephalopathies is changing our practice.

Trial registration: Retrospectively registered. Patient data were reported to the "Commission Nationale Informatique et Libertés" under the number 2106953.

Keywords: Neonatal seizures, Maintenance therapy, Etiology, Valproic acid, Levetiracetam, Carbamazepine

\section{Background}

Seizures are the most frequent neurological symptom during the neonatal period [1]. The neonatal brain is characterized by a high level of synaptogenesis and neuronal plasticity that explains a physiological hyperexcitability, and thus a vulnerability to seizure $[2,3]$.

\footnotetext{
* Correspondence: baudou.e@chu-toulouse.fr

'Unit of Pediatric Neurology, Hôpital des Enfants, CHU Toulouse, 330 av de Grande Bretagne-TSA, 31059 Toulouse Cedex, France

${ }^{3}$ Service de Neurologie Pédiatrique, Hôpital des Enfants, CHU Toulouse, 330 avenue de Grande Bretagne-TSA, 31059 Toulouse Cedex, France

Full list of author information is available at the end of the article
}

The occurrence is between 1 and 3 per 1000 term newborns [4-7].

Etiologies are mainly symptomatic. They are divided into: vascular (hypoxic-ischemic encephalopathy (HIE), ischemic infarction, intracranial hemorrhage); infectious (intracranial infections); metabolic (metabolic or electrolyte disorder, inborn error of metabolism), and malformation (congenital malformations of the central nervous system). The incidence of epileptic syndromes is less than $10 \%$ [8]. On the one hand, benign familial neonatal convulsions (BFNC) and benign idiopathic neonatal convulsions are associated with a favorable outcome. On the

(c) The Author(s). 2019 Open Access This article is distributed under the terms of the Creative Commons Attribution 4.0 International License (http://creativecommons.org/licenses/by/4.0/), which permits unrestricted use, distribution, and reproduction in any medium, provided you give appropriate credit to the original author(s) and the source, provide a link to the Creative Commons license, and indicate if changes were made. The Creative Commons Public Domain Dedication waiver (http://creativecommons.org/publicdomain/zero/1.0/) applies to the data made available in this article, unless otherwise stated. 
other hand, early myoclonic encephalopathy and early infantile epileptic encephalopathy have poor prognoses. The risk of developing epilepsy is about $17.9 \%$ according to a meta-analysis [9]. Etiology and electroencephalographic profile are important risk factors. However, designing a universal scoring system capable of providing early prognostic information on epilepsy development seems difficult because of the uncertainty related to etiology and gestational age [10].

The World Health Organization recommends treatment of a crisis lasting more than $3 \mathrm{~min}$ or repeated clinical or subclinical crises [11]. There is no strong recommendation about maintenance therapy: indication criteria, drug, or duration. The administration of maintenance therapy should be reserved for newborns at risk of seizure recurrence. This risk is less than $10 \%$ when seizure control is achieved and both the neurological examination and electroencephalogram (EEG) are normal. Phenobarbital is the acute treatment of choice in neonatal seizures [12, 13]. However, phenobarbital has been found to increase neuronal apoptosis in newborn rats and to have cognitive side effects in infants $[13,14]$. This leads to the prescription of a different antiepileptic drug in maintenance therapy [15]. The duration should be as short as possible [16]. The criteria for discontinuing treatment should be both clinical and electroencephalographic [17].

The aim of this study was twofold: to investigate the incidence of etiologies of neonatal seizures in full-term neonates at the University Children's Hospital of Toulouse, France and to report our practices concerning the maintenance antiepileptic therapy used.

\section{Methods}

\section{Study population}

This is a retrospective cohort study of consecutive full-term neonates admitted to the University Children's Hospital of Toulouse from January 2004 to October 2014 with suspicion of seizure during the first 28 days after birth. Neonates whose gestational age was over 37 weeks of amenorrhea with clinical convulsions and an abnormal EEG recording either clinical or subclinical convulsions (spike discharge greater than $10 \mathrm{~s}$ ) or epileptic abnormalities (spikes, polypoints, wave spikes ...) were included. The exclusion criteria were: prematurity, abnormal non-epileptic movements, normal EEG. Failure to perform an EEG due to an early death of the patient was not an exclusion criterion if the context and the clinical data were highly suggestive of seizures.

\section{Scheme for neonatal seizure treatment in our center}

Emergency treatment is given in case of repeated or prolonged seizures to stop them: as first-line treatment, intravenous (IV) phenobarbital, then IV phenytoin if ineffective. Some patients could have received first-line treatment before admission in our center, and in this case intrarectal diazepam could have been used. Oral maintenance anticonvulsant treatment (valproic acid (VPA)), levetiracetam, carbamazepine ...) is started quickly when there is high risk of seizure recurrence. VPA, then levetiracetam is usually the first-line drug of choice for generalized seizures and carbamazepine in focal seizures. The risk factors for seizure recurrence are: status epilepticus, the need to use several emergency treatments to stop seizures, etiology other than a simple easily correctable hydroelectrolytic disorder, abnormal neurological examination or persistent abnormalities in EEG. A neuropediatric evaluation takes place at 3-4 months with EEG. If the patient has not had a seizure recurrence, the neurological examination is satisfactory, and the EEG does not show any epileptic abnormalities, the treatment is stopped gradually over several weeks. Otherwise it is continued 3 months or more depending on the etiology of convulsions.

\section{Methods}

Neonates diagnosed with seizures were identified through a search in the digital database of the medical information center of the Hospital. Clinical data was extracted from computerized and paper medical records.

Data gathered for each patient included gender, gestational age and place where the first seizure occurred. Neonatal seizures were characterized by type (focal, clonic, subtle, myoclonic, tonic, spasms, tonic-clonic, and infraclinical), as reported in the records, and for newborns presenting several type of seizures, the main type was selected. The delay between birth and first seizure, and the presence of status epilepticus were also reported. Status epilepticus was defined as a convulsion lasting more than $15 \mathrm{~min}$ or more than three seizures in $30 \mathrm{~min}$.

The following paraclinical data were collected: EEG reports (seizures recorded, paroxystic events such as spikes), cerebral tomodensitometry reports (TDM), and cerebral MRI reports.

We report the seizure etiology for each patient. The diagnosis of HIE was based on a severe metabolic acidemia (umbilical cord or first neonatal blood sample $\mathrm{pH}$ of $<7.0$ ) and/or 5-min Apgar score of $<6$ and/or fetal distress (abnormal fetal heart rate or meconium-stained amniotic fluid), associated with a clinical examination corresponding to Sarnat's score of two or three. Ischemic infarction, cerebral malformations and intracranial hemorrhage, including intraventricular hemorrhage, were diagnosed using neuro-imaging. A diagnosis of bacterial or viral infection required findings of biological inflammatory syndrome in plasma and cerebrospinal fluid or highlighting of the virus or bacterium in the 
cerebrospinal fluid. The diagnosis of hydroelectrolytic disorders was based on the analysis of a blood sample. Inborn error of metabolism was diagnosed by metabolic tests, with or without genetic confirmation. There is no genetic confirmation of BFNC in our study.

Regarding anti-seizure medication, we distinguished between acute therapy administered intravenously to stop a lasting or repeated crisis and maintenance therapy administered orally to avoid the recurrence of convulsion.

We report the type of drug used and the duration of treatment.

We also report the short and mid-term outcomes (death, epilepsy) and the duration of follow-up.

\section{Statistics}

Study results are presented as numbers and percentages. We performed a comparative analysis between the group of all neonates treated with levetiracetam and a group of neonates treated with valproic acid paired with the gender and type of seizure and adjusted in multivariate analysis of the etiology with the Stata software, version 14.

\section{Ethics}

Patient data were reported to the "Commission Nationale Informatique et Libertés" under the number 2106953.

\section{Results}

\section{Population}

319 full-term newborns with suspected neonatal seizures were admitted to the University Children's Hospital of Toulouse from January 2004 to October 2014. Of the 243 who were included (Fig. 1), 59\% were male and $41 \%$ female. The average gestational age was 39 weeks of amenorrhea (range 37-42) and the average birth weight was $3.320 \mathrm{~kg}$ (range 1.96-4.8), with $31 \%$ births by cesarean section, and $41 \%$ spontaneous natural births. The place where the first seizure occurred was known for 213 newborns: 9\% at home after maternity unit discharge, $63 \%$ in a secondary hospital, and $14 \%$ in our center. The initial place of hospitalization was the neonatal intensive care unit (53\%), the neonatology unit (43\%) and the Department of Neuropediatrics (4\%).

\section{Seizures}

Seizures occurred within the first day in $57 \%$ of neonates, within $24-72 \mathrm{~h}$ in $21 \%$, and after $72 \mathrm{~h}$ in $22 \%$. Only $48 \%$ had electrographic confirmation of the seizures but $75 \%$ had paroxystic events on the EEG. Thirty three percent of neonates presented a status epilepticus. According to the data gathered from patient records, the main type of seizure was focal clonic (35\%), followed by multifocal clonic (24\%), subtle (20\%), myoclonic (2\%), tonic $(6 \%)$, spasms (1\%), tonic-clonic (6\%), and infraclinical (6\%). The mean

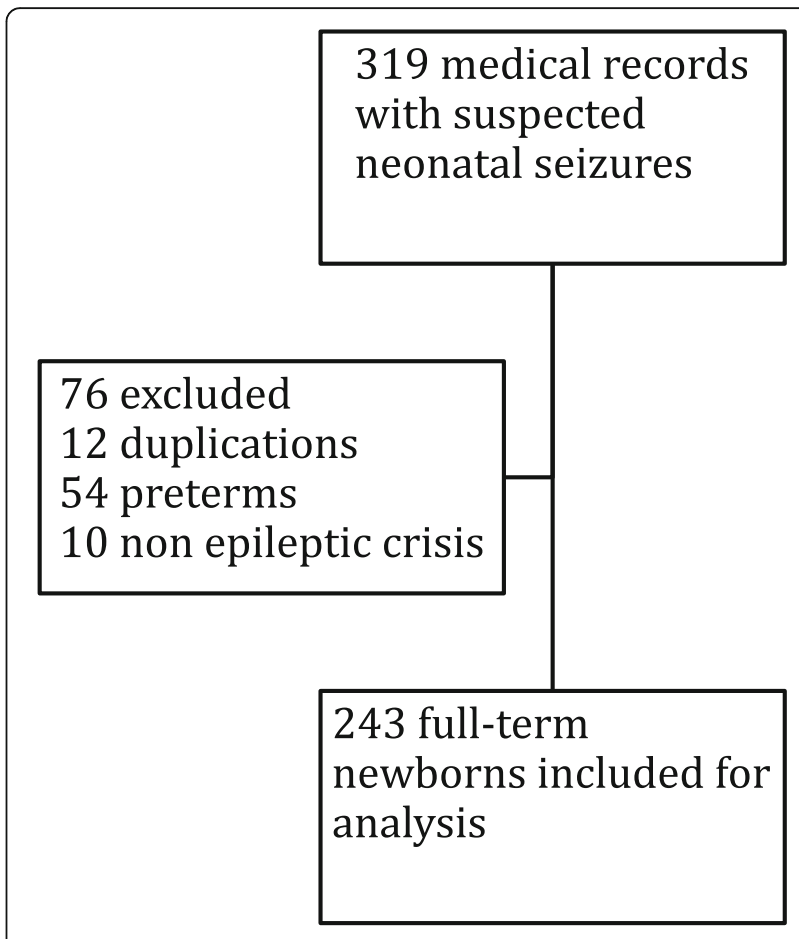

Fig. 1 Flow-chart of included newborns

number of electroencephalograms during hospitalization was 2.23 (range 0-7). Four newborns died before an electroencephalogram was performed and eleven patients' EEGs showed a "suppression-burst" pattern.

\section{Etiology}

The etiology of neonatal seizures is presented in Table 1 . Perinatal asphyxia was the most common cause of seizures in our study group (37\%). One patient presented bacterial meningitis, resolved by antibiotic treatment. An inborn error of metabolism was attributed to a patient who presented a severe and prolonged hypoglycemia in the neonatal period and the need of a specific diet in the first months of life, without final diagnosis. Two patients with severe neonatal seizures who developed encephalopathy and pharmacoresistant epilepsy, but with a negative etiologic screening, were classified under severe epileptic syndromes. In 16 patients (6,5\%), a diagnosis could not be made based on history, physical examination, laboratory tests, imaging techniques, and metabolic screening tests. Cerebral TDM was performed in $88 \%$ of patients. Cerebral MRI was performed later in $65 \%$ of patients.

\section{Outcomes}

The median age of follow-up was 18 months (range 1 month -11 years) for patients having survived the neonatal period. 
Table 1 Etiology of neonatal seizures in term newborns at the University Children's Hospital of Toulouse from 2004 to 2014

\begin{tabular}{|c|c|c|c|c|c|c|c|}
\hline & & & & & & Death & Epilepsy \\
\hline \multirow[t]{4}{*}{ Vascular } & $156(64 \%)$ & $\mathrm{HIE}$ & $91(37 \%)$ & HIE II & $63(26 \%)$ & $37(41 \%)$ & $7(13 \%)$ \\
\hline & & & & HIE III & $28(11 \%)$ & & \\
\hline & & Ischemic infarction & $36(15 \%)$ & & & & $3(9 \%)$ \\
\hline & & Intracranial hemorrhage & $29(12 \%)$ & & & & $3(9 \%)$ \\
\hline \multirow[t]{5}{*}{ Infectious } & $19(22 \%)$ & Bacterial meningitis & $16(7 \%)$ & Streptococcus & $11(5 \%)$ & $4(21 \%)$ & $1(7 \%)$ \\
\hline & & & & E Coli & $4(2 \%)$ & & \\
\hline & & & & Unknown & $1(0,5 \%)$ & & \\
\hline & & Viral meningoencephalitis & $3(1 \%)$ & HSV & $2(1 \%)$ & & \\
\hline & & & & Enterovirus & $1(0,5 \%)$ & & \\
\hline \multirow[t]{6}{*}{ Metabolic } & $14(6 \%)$ & Metabolic or electrolytic & $9(4 \%)$ & Hypoglycemia & $4(2 \%)$ & & $1(11 \%)$ \\
\hline & & & & Hypernatremia & $3(1 \%)$ & & \\
\hline & & & & Hypocalcemia & $2(1 \%)$ & & \\
\hline & & Inborn errors of metabolism & $5(2 \%)$ & Citrullinemia & $1(0,5 \%)$ & $4(57 \%)$ & $2(67 \%)$ \\
\hline & & & & Peroxisomal disease & $3(1 \%)$ & & \\
\hline & & & & Unknown & $1(0,5 \%)$ & & \\
\hline \multirow[t]{4}{*}{ Malformation } & $11(5 \%)$ & TORCH syndromes & $2(1 \%)$ & & & $4(33 \%)$ & $6(75 \%)$ \\
\hline & & Neurocutaneous syndromes & $2(1 \%)$ & Sturge-Weber syndrome & $1(0,5 \%)$ & & \\
\hline & & & & Tuberous sclerosis & $1(0,5 \%)$ & & \\
\hline & & Gyration abnormalities & $7(3 \%)$ & & & & \\
\hline \multirow[t]{5}{*}{ Epileptic Syndromes } & $27(11 \%)$ & Benign & $17(7 \%)$ & $\begin{array}{l}\text { Benign familial neonatal } \\
\text { convulsions }\end{array}$ & $7(3 \%)$ & & $1(6 \%)$ \\
\hline & & & & $\begin{array}{l}\text { Benign idiopathic neonatal } \\
\text { convulsions }\end{array}$ & $10(4 \%)$ & & \\
\hline & & Severe & $10(4 \%)$ & Early myoclonic encephalopathy & $2(1 \%)$ & $4(40 \%)$ & $6(100 \%)$ \\
\hline & & & & $\begin{array}{l}\text { Early infantile epileptic } \\
\text { encephalopathy }\end{array}$ & $6(3 \%)$ & & \\
\hline & & & & Others & $2(1 \%)$ & & \\
\hline Unknown & $16(7 \%)$ & & & & & & $1(8 \%)$ \\
\hline Total & 243 & & & & & $53(22 \%)$ & $31(16 \%)$ \\
\hline
\end{tabular}

HIE hypoxic-ischemic encephalopathy, E coli Escherichia coli, HSV Herpes Simplex Virus, TORCH Toxoplasmosis, Other Agents, Rubella, Cytomegalovirus, and Herpes simplex

Fifty-three patients died (22\%): thirty-seven HIE, four intracranial infections, four inborn errors of metabolism, four severe epileptic syndromes and four cerebral malformations. Forty- five deaths occurred during the first month of life and eight before the third year of life.

The incidence of epilepsy among patients was $15 \%$. The onset was neonatal in 17 patients. In the other cases, the median age of onset was 10 months. In our cohort, $100 \%$ of patients with severe epileptic syndromes, $80 \%$ with inborn errors of metabolism, and $75 \%$ with cerebral malformations developed epilepsy.

\section{Acute anti-seizure medication}

One third of our cohort received one drug, one third two drugs, and one third, three or more. Phenobarbital was administered to 199 patients (82\%), diazepam to 111
(46\%) and phenytoin to 79 (32\%). Vitamin therapy was tried on only ten patients without success. $86 \%$ of newborns treated with diazepam needed a second-line treatment that was phenobarbital in most cases, versus $43 \%$ of newborns treated with phenobarbital.

\section{Maintenance therapy}

Only $27 \%$ of the patients did not receive maintenance therapy: half of them died during hospitalization, and the other half had a few seizures quickly controlled by a single administration of an acute treatment, followed by normal clinical and electroencephalographic post-seizure examinations. In all, 180 patients (72\%) were discharged with a maintenance therapy. The therapy used is reported in Fig. 2.

In our cohort, the choice of treatment depended mainly on the etiology (Fig. 3). Strokes and severe epileptic 


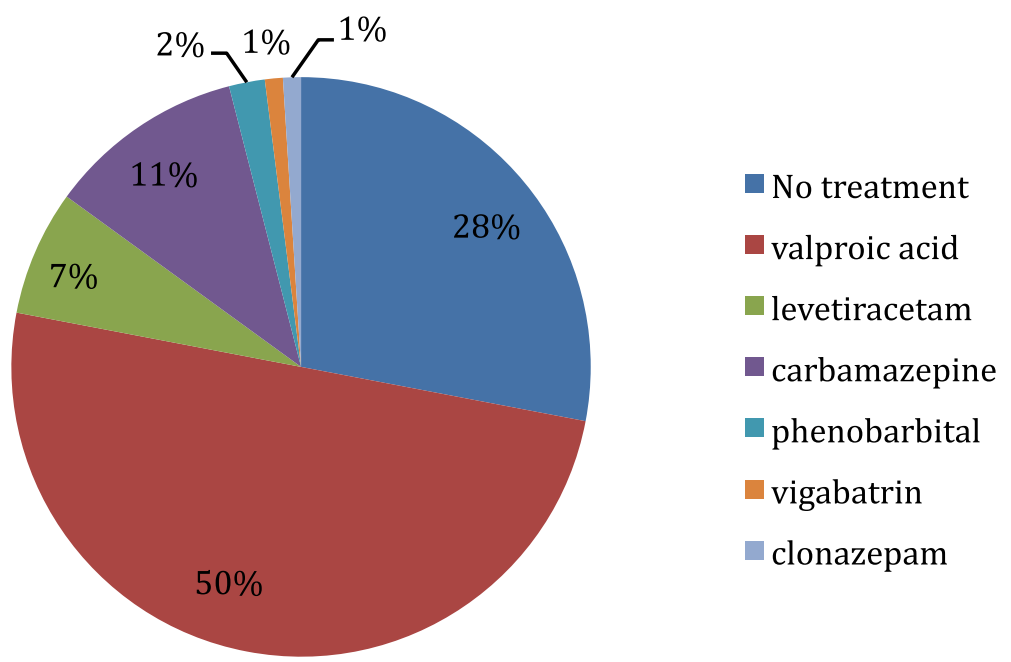

Fig. 2 Anticonvulsivant maintenance therapy used in 243 term newborns with neonatal seizures at the University Children's Hospital of Toulouse from 2004 to 2014

syndromes always benefited from a long-term treatment. Strokes, infections and malformations, which usually caused partial seizures, were treated with valproic acid or carbamazepine. Phenobarbital, vigabatrin and clonazepam were used for the difficult cases of drug resistant seizures. Carbamazepine and levetiracetam have been used since 2010 .

The mean duration of the first maintenance treatment was 5.2 months for patients who did not develop epilepsy, 4.9 months (SD: 1.61) in hypoxic-ischemic encephalopathy, 4.2 months (SD: 1.69) in ischemic infarction, 4.8 months (SD: 2.14) in intracranial hemorrhage, 4.3 months (SD: 2.26) in intracranial infections, 1.71 (SD: $1.45)$ in metabolic or electrolyte disorder, 8.69 months (SD: 9.84) in congenital malformations of the central nervous system, 8.5 months (SD: 5.6) in benign epileptic syndromes, and 4.06 months (SD: 2.78) in unknown diagnosis. For patients who developed epilepsy, the treatment lasted at least 2 years. All patients having inborn error of metabolism and severe epileptic syndromes developed pharmacoresistant epilepsy and/or died, and the treatment needed to be switched or associated quickly.

We compare seventeen newborns treated with valproic acid matched to the 17 newborns treated with levetiracetam by the gender and main convulsion type variables and adjusted for the etiology variable. In each group there were $59 \%$ boys and $41 \%$ girls, $47 \%$ of clonic seizures, $23 \%$ of focal seizures, $29 \%$ of subtle seizures, $6 \%$ of myoclonic and $12 \%$ of subclinical seizures. Bivariate analysis showed that patients treated with valproic acid received significantly higher numbers of acute antiepileptic drugs compared to patients treated with levetiracetam (Table 2). This difference remained statistically significant in multivariate analysis when considering the type of antiepileptic treatment used in acute first-line therapy. Treatments with levetiracetam and valproic acid were introduced on average with a delay from the first crisis of respectively 1.2 days and 2 days. In terms of outcome, with the low frequency of events, the small size of our groups and the differences in etiology between the two groups, no significant results were found.

\section{Evolution}

Analysis year by year shows a stability of seizures diagnostic rate, use of MRI and duration of maintenance therapy. However, since 2010, new maintenance therapies have been used (Fig. 4).

\section{Discussion}

This study reports the experience of our center concerning the long-term drug management of neonatal seizures depending on etiologies.

The main etiology of full-term neonates admitted to our center because of neonatal seizures was HIE (37\%). Compared to a recent American prospective cohort of 426 term and preterm neonates based on EEG diagnosis, the distribution of the various etiologies is similar [18]. In our population, the incidence of each etiology was: $37 \%$ (versus $38 \%$ in the Glass cohort study) hypoxic-ischemic encephalopathy, $12 \%$ (11\%) ischemic infarction, 15\% (18\%) intracranial hemorrhage, $8 \%(4 \%)$ intracranial infections, 3\% (4\%) metabolic or electrolyte disorder, $2 \%(3 \%)$ inborn errors of metabolism, $5 \%$ (4\%) congenital malformations of the central nervous system, and $11 \%$ (6\%) epileptic syndromes. The etiology was unknown in 16 patients. The etiology was not always found in the neonatal 


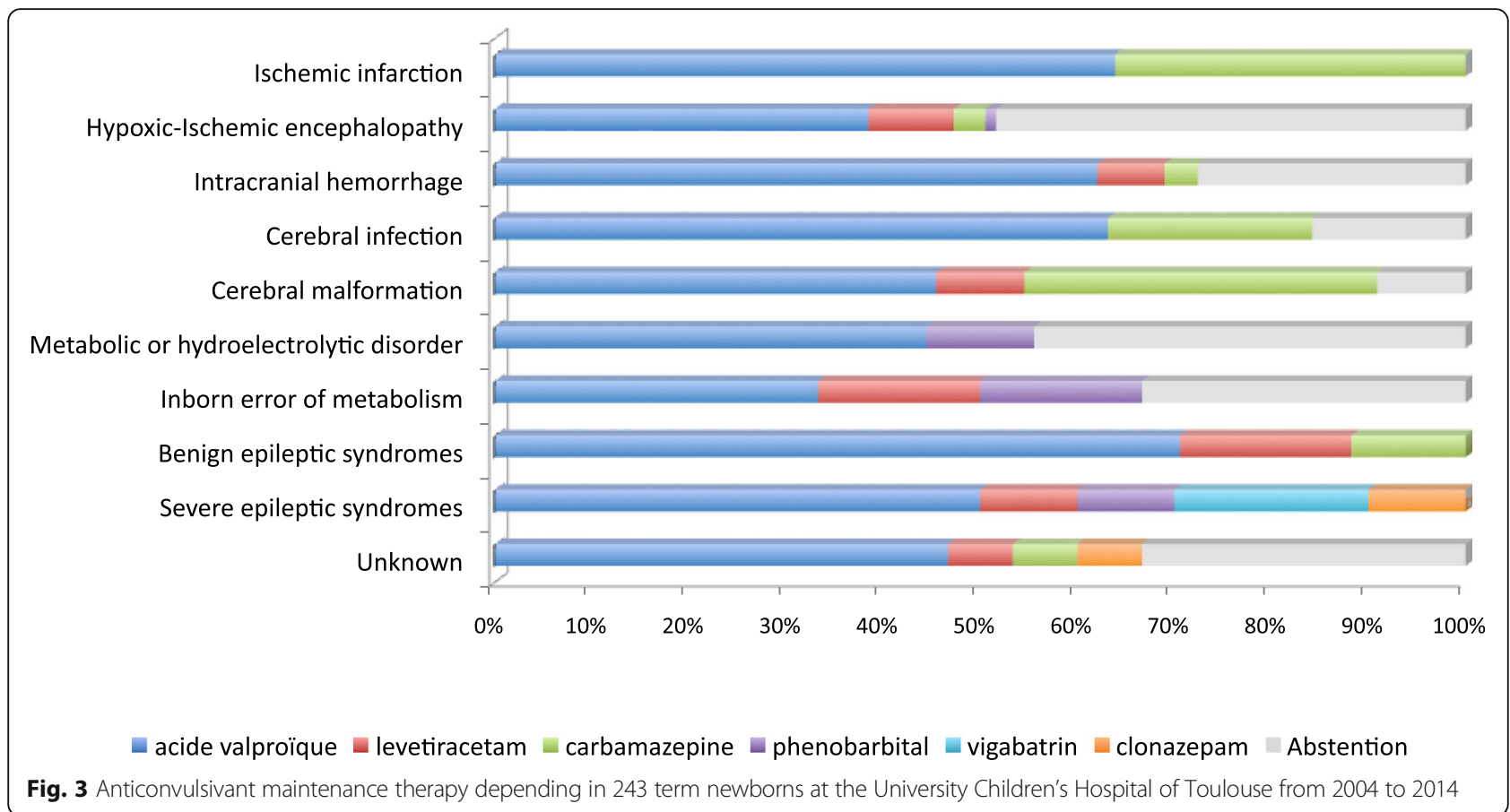

period and 7\% (9\%) of our cohort did not have a diagnosis at the end of the following period.

In this study, the overall incidence of seizures was 0.9 per 1000 full-term live births per year in the Midi-Pyrénées region. In other studies, this incidence was between 1 and 3 per 1000 live births [4-7]. The diagnosis of seizures was based mainly on clinical observation, with a low rate $(48 \%)$ of electroencephalographic confirmation. Consequently, the incidence of neonatal seizures in our population could have been underestimated. [19] This study highlights the need for our center to improve the use of prolonged EEG video to better diagnose neonatal seizures, especially in newborns at risk.

During neonatal admission, $18.5 \%$ of patients died. This is in line with previous publications of Mastrangelo et al. [20] (21\%) and Glass et al. (17\%) [12]. In our cohort, 15\% developed epilepsy. A meta-analysis reported a similar rate of $17.9 \%$ in the literature. Etiologies with a poor prognosis were HIE, congenital malformations of the central nervous system, inborn error of metabolism and epileptic syndromes.

Regarding the acute treatment of neonatal seizures, we note that diazepam administered as a first-line treatment usually shows low efficacy. Despite its limited efficacy, diazepam is still used because of the ease of its intra-rectal administration in newborns that still do not have intravenous access. Administration of diazepam should be avoided because it leads to polymedication that will increase the risk of side effects in the neonate and may delay the establishment of an emergency venous route for the administration of phenobarbital.
A maintenance therapy was prescribed for 180 newborns (72\%). In a previous study, Bartha et al. [21] reported a rate of $75 \%$ of newborns discharged with an antiepileptic therapy. The type of drug used, and duration were not reported in this study. Factors that determined the use of a maintenance therapy were abnormal EEG, neuro-imaging and second-line or further acute antiepileptic treatment in Bartha's study.

Valproic acid was commonly used in our cohort whatever the etiology of seizures. While other centers use phenobarbital in maintenance treatment, the choice to use other molecules (valproic acid, carbamazepine ...) has been done in our center to avoid neurodevelopmentally related adverse effects related to long-term use of phenobarbital [15]. However, the use of valproic acid does not seem completely safe since serious adverse effects such as hyperammonemic encephalopathy are reported in neonates free of any metabolic disease, apart from overdose [22]. Since 2010, we have used new antiepileptic drugs such as carbamazepine and levetiracetam. Carbamazepine [23, 24] has been used in partial seizures due to stroke, infection, or malformation. Levetiracetam [25-30] has been used in other types of seizures, especially when valproic acid [31-34] was contraindicated, i.e. when liver enzymes were disturbed or when a metabolic disease was suspected. Although, levetiracetam is more and more used, we recall that there is still no marketing authorization for this drug in newborns. Phenobarbital has not been used since 2009 because of its potential cognitive side effects in infants and newborns and the difficulty of finding the correct dose (seizure-free without drowsiness). Vigabatrin 
Table 2 Difference between acute anti-seizure medication in the group treated with valproic acid and the group treated with levetiracetam matched by gender and main convulsion type variables

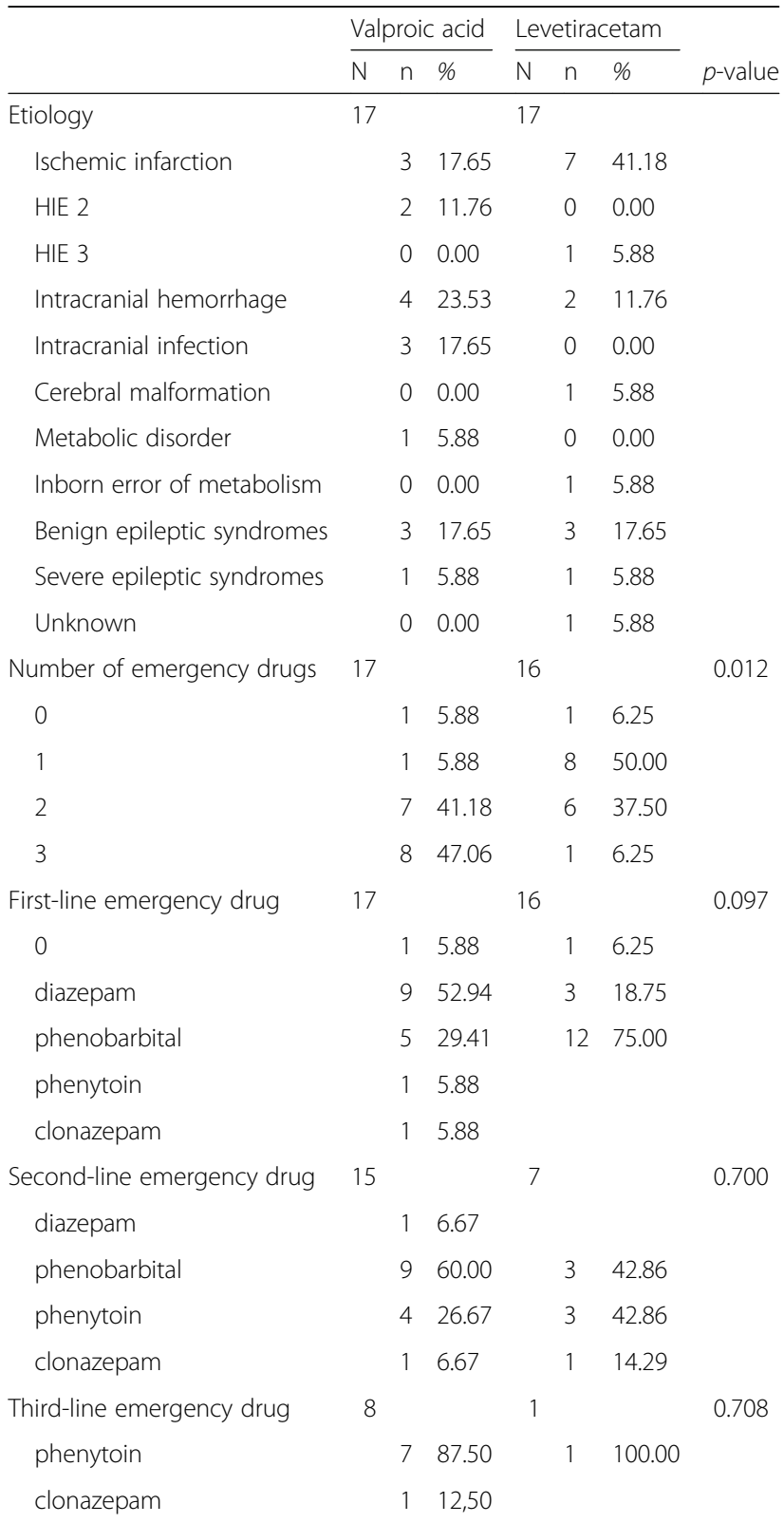

HIE hypoxic-ischemic encephalopathy

has rarely been used in our practice because of the incidence of visual side effects [35-39]. Because of those ophthalmologic side effects, it was only indicated when seizures were difficult to control. [40, 41] Clonazepam was used in similar indications. The small numbers of patients receiving levetiracetam, carbamazepine, vigabatrin, phenobarbital or clonazepam does not allow us to make statistical comparisons about the efficacy and the tolerance of different anti-epileptic treatments, especially because the etiologies of neonatal seizures are different in this group and it is the most important prognostic factor. The subgroup analysis comparing patients treated with levetiracetam, which is now widely used, with a group of patients treated with valproic acid, did not show any difference in the outcome (death and epilepsy) of the patient, maybe because of low effectives. However, it is interesting to note that the number of anticonvulsants used urgently in the treatment of newborns for whom long-term treatment with levetiracetam is set up is significantly lower. This is all the more important since it is known that the risk of adverse effects increases when several treatments are combined.

Recent studies support a targeted therapeutic approach for genetic epileptic encephalopathies based on the molecular dysfunction. For example, KCNQ2 and $S C N 2 A$ genes are involved in neonatal epilepsy. Their mutations result in sodium and potassium channel dysfunctions. Carbamazepine, is a sodium channel blocker, that also modulates potassium channels, co-localized at the neuronal membrane. Low dose of carbamazepine are effective in this indication and it could be considered as first-line treatment [42-44]. A better understanding of the physiopathology of neonatal epilepsies will help us to determine the more effective antiepileptic drugs to use.

In our cohort, the treatment was discontinued after a control EEG, on the average after 5 months of treatment. The duration depended on the severity of the initial profile, seizure recurrence, etiology and the presence of paroxysmal elements in the electroencephalogram. French guidelines published in 2016 about the treatment of neonatal cerebral arterial infarction, recommend to stop antiepileptic drug $72 \mathrm{~h}$ after the last seizure if the clinical examination and EEG are normal or at discharge if there are moderate abnormalities [45]. Achieving earlier discontinuance of maintenance therapy seems to be a major challenge in our practices to limit side effects of antiepileptic drugs.

This study has some biases. The lack of systematic confirmation of seizures at EEG, due to a low use of aEEG, may have led to the inclusion of patients with abnormal non-epileptic movements. The support in different services with the absence of a common protocol of care leads to a great variability of practices. Finally, the retrospective nature induces some missing data and the size of our cohort did not allow us to evaluate the efficacy and tolerance of the different treatments. However, this study allows us to improve the management of neonatal seizures in our center, with the increase of the use of prolonged video EEG, the cessation of diazepam use in the acute treatment of seizures, and the limitation of the duration of the maintenance therapy. We report pratices that have changed during the study period and since the end of data collection and that can't be used as current practices now. 


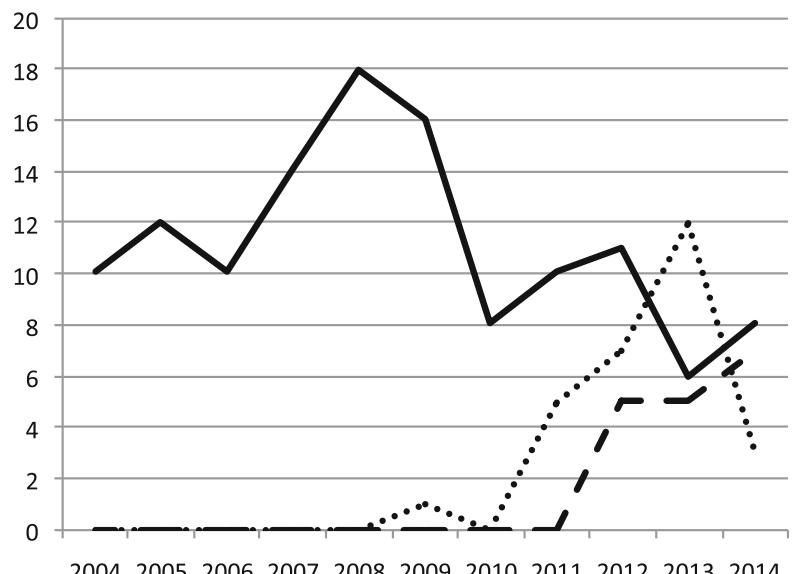

\section{- valproïc acid -.... carbamazepine \\ - -levetiracetam}

20042005200620072008200920102011201220132014

Fig. 4 Anticonvulsivant maintenance therapy in neonatal seizures in 243 term newborns at the University Children's Hospital of Toulouse: Evolution of pratices from 2004 to 2014

\section{Conclusions}

In conclusion, despite the lack of systematic electroencephalographic diagnoses, we report a neonatal cohort of full-term newborns comparable with other studies. Although neonatal seizures are often occasional events and the risk of developing epilepsy is about $15 \%$, depending on the etiology, we frequently used a maintenance antiepileptic treatment. No current guidelines allow us to determine the best choice of drug to use in this indication. In our practice, valproic acid was the most commonly prescribed when liver function is normal and metabolic disease excluded. However, the arrival on the market of new antiepileptic drug, and a better understanding of the physiopathology of genetic encephalopathies is changing our practice. Additional studies are necessary to establish recommendations concerning the long-term management of neonatal seizures according to their etiology.

\section{Abbreviations}

BFNC: Benign familial neonatal convulsions; EEG: Electroencephalogram; HIE: Hypoxic-ischemic encephalopathy; TDM: Tomodensitometry

\section{Acknowledgements}

Not applicable.

SARL AMPLUS for providing language editing service.

This research did not receive any specific grant from funding agencies in the public, commercial, or not-for-profit sectors.

\section{Funding}

No funding.

\section{Availability of data and materials}

The datasets used and/or analyzed during the current study are available from the corresponding author on reasonable request.

\section{Authors' contributions}

EB collected data and wrote the first draft. CHL and CC contributed to the elaboration of the ideas developed in the manuscript and made critical amendments. CD provided the statistical analysis. All authors read and approved the final manuscript.

\section{Ethics approval and consent to participate}

Retrospectively registered. Patient data were reported to the "Commission Nationale Informatique et Libertés" under the number 2106953. Nonopposition verbal consent was obtained from the parents of the subjects.

\section{Consent for publication}

Not applicable.

\section{Competing interests}

The authors declare that they have no competing interests.

\section{Publisher's Note}

Springer Nature remains neutral with regard to jurisdictional claims in published maps and institutional affiliations.

\section{Author details}

${ }^{1}$ Unit of Pediatric Neurology, Hôpital des Enfants, CHU Toulouse, 330 av de Grande Bretagne-TSA, 31059 Toulouse Cedex, France. ²Biostatistiques, Informatique Médicale, UMR 1027 Inserm, Université Paul Sabatier, Toulouse, France. ${ }^{3}$ Service de Neurologie Pédiatrique, Hôpital des Enfants, CHU Toulouse, 330 avenue de Grande Bretagne-TSA, 31059 Toulouse Cedex, France.

Received: 4 October 2018 Accepted: 11 April 2019

Published online: 29 April 2019

\section{References}

1. Volpe JJ. Neurology of the newborn. 5th ed. Philadelphia: Saunders; 2008

2. Rakhade SN, Jensen FE. Epileptogenesis in the immature brain: emerging mechanisms. Nat Rev Neurol. 2009;5:380-91.

3. Sanchez RM, Jensen FE. Maturation aspects of epilepsy mechanisms and consequences for the immature brain. Epilepsia. 2001;42(5):577-85.

4. Vasudevan C, Levene M. Epidemiolgy and aetiology of neonatal seizures. Semin Fetal Neonatal Med. 2013:18(4):185-91.

5. Lanska MJ, Lanska DJ, Baumann RJ, et al. A population-based study of neonatal seizures in Fayette County, Kentucky. Neurology. 1995;45:724-32.

6. Ronen GM, Penney S, Andrews W. The epidemiology of clinical neonatal seizures in Newfoundland: a population-based study. J Pediatr. 1999;134:71-5.

7. Saliba RM, Annegers JF, Waller DK, et al. Incidence of neonatal seizures in Harris County, Texas, 1992-1994. Am J Epidemiol. 1999;150:763-9.

8. Hart AR, Pilling EL, Alix JJP. Neonatal seizures- part 2 : aetiology of acute symptomatic seizures, treatments and the neonatal epilepsy syndromes. Arch Dis Child Educ Pract Ed. 2015;100:226-32.

9. Pisani F, Facini $C$, Pavlidis $E$, et al. Epilepsy after neonatal seizures : literature review. Eur J Paediatr Neurol. 2015 Jan;19(1):6-14. 
10. Soltirovska-Salamon A, Neubauer D, Petrovcic A, et al. Risk factors and scoring system as a prognostic tool epilepsy after neonatal seizures. Pediatr Neurol. 2014;50(1):77-84.

11. World Health Organization. Guidelines on neonatal seizures. Geneva: WHO; 2011

12. Glass HC, Kan J, Bonifacio SL, Ferriero DM. Neonatal seizures: treatment practices among term and preterm. Pediatr Neurol. 2012:46:111-5.

13. Wickstrom R, Hallberg B, Bartocci M. Differing attitudes toward phenobarbital use in the neonatal period among neonatologists and child neurologists in Sweden. Eur J Paediatr Neurol. 2013;17:55-63.

14. Bittigau P, Sifringer M, Genz K, et al. Antiepileptic drugs and apoptotic neurodegeneration in the developing brain. Proc Natl Acad Sci U S A. 2002; 99:15089-94.

15. Farwell JR, Lee JY, et al. Phenobarbital for febrile seizures effects on intelligence and on seizure recurrence. N Engl J Med. 1990;322:364-9.

16. Koenigsberger MR, Caballar-Gonzaga FJ, Dierkes T. Neonatal seizures : the beginning and interruption of the treatment. Rev Neurol. 1997; 25(141):706-8.

17. Scarpa $P$, Chierici $R$, Tamisari $L$, et al. Criteria for discontinuing neonatal seizure therapy: a long- term appraisal. Brain and Development. 1983;5: 541-8.

18. Glass HC, Shellhaas RA, Wusthoff CJ, et al. Contemporary profile of seizures in neonates : a prospective cohort study. J Pediatr. 2016;174:98-103.

19. Murray DM, Boylan GB, Ali I, Ryan CA, Murphy BP, Connolly S. Defining the gap between electrographic seizure burden, clinical expression and staff recognition of neonatal seizures. Arch Dis Child Fetal Neonatal Ed. 2008;93: 187-91.

20. Mastrangelo M, Van Lierde A, Bray M, et al. Epilepstic seizures, epilepsy and epieptic syndromes in newborns : a nosological approach of 94 new cases by the 2001 proposed diagnostic scheme for people with epileptic seizures and epilepsy. Seizure. 2005;14(5):304-11.

21. Bartha Al, Shen J, Kat KH, et al. Neonatal seizures : Muticenter variability in current treatment Pratices. Pediatr Neurol. 2007:37:85-90.

22. Baudou E, Benevent J, Montastruc JL, Touati G. Hachon LeCamus C. adverse effects of treatment with Valproic acid during the neonatal period. Neuropediatrics. 2018. https://doi.org/10.1055/s-0038-1676035.

23. Singh B, Singh P, Al Hifzi I, et al. Treatment of neonatal seizures with carbamazepine. J Child Neurol. 1996;11:378-82.

24. Hoppen T, ErichElger C, Bartmann P. Carbamazepine in phenobarbital-non responders: experience with ten preterm infants. Eur J Pediatr. 2001;160: 444-7.

25. Weinstock A, Ruiz M, Gerard D, Toublanc N, Stockis A, Farooq O, et al. Prospective open-label, single-arm, multicenter, safety, tolerability, and pharmacokinetic studies of intravenous levetiracetam in children with epilepsy. J Child Neurol. 2013 Nov;28(11):1423-9.

26. Glauser TA, Ayala R, Elterman RD, et al. Double-blind placebo-controlled trial of adjunctive levetiracetam in pediatric partial seizures. Neurology. 2006;66: 1654-60.

27. Khan O, Chang E, Cipriani C, Wright C, Crisp E, Kirmani B. Use of intravenous levetiracetam for management of acute seizures in neonates. Pediatr Neurol. 2011;44:265-9.

28. Rakshasbhuvankar A, Rao S, Kohan R, Simmer K, Nagarajan L. Intravenous levetiracetam for treatment of neonatal seizures. J Clin Neurosci. 2013;20: $1165-7$.

29. Abend NS, Gutierrez-Colina AM, Monk HM, Dlugos DJ, Clancy RR. Levetiracetam for treatment of neonatal seizures. J Child Neurol. 2011;26: 465-70.

30. Ramantani G, Ikonomidou C, Walter B, et al. Levetiracetam: safety and efficacy in neonatal seizures. Eur J Paediatr Neurol. 2011;15(1):1-7.

31. Steinberg A, Shalev R, Amir N. Valproic acid in neonatal status convulsivus. Brain Dev. 1986;8(3):278-820.

32. Alfonso I, Alvarez LA, Dunoyer C, Yelin K, Papazian O. Intravenous valproate dosing in neonates. J Child Neurol. 2000;15(12):827-9.

33. Gal P, Oles KS, Gilman JT, Weaver R. Valproic acid efficacy, toxicity, and pharmacokinetics in neonates with intractable seizures. Neurology. 1988; 38(3):467-71.

34. Irvine-Meek JM, Hall KW, Otten NH, et al. Pharmacokinetic study of valproic acid in a neonate. Pediatr Pharmacol. 1982;2(4):317-21.

35. Graham D. Neuropathology of vigabatrin. Br J Clin Pharmac. 1989:27:43S-5S.

36. Butler WH, Ford GP, Newberne JW. A study of the effects of vigabatrin on the central nervous system and retina of Sprague Dawley and Listerhooded rats. Toxicol Pathol. 1987;15:143-8.
37. Eke T, Talbot JF, Lawden MC. Severe persistent visual field constriction associated with vigabatrin. BMJ. 1997:314:180.

38. Maguire MJ, Hemming K, Wild JM, et al. Prevalence of visual fiels loss following exposure to vigabatrin therapy: a systematic review. Epilepsia. 2010;51(12):2123-31.

39. Ingster-Moati I, Orssaud C. Protocole de surveillance ophtalmologique des patients traites par antipaludeens de synthese ou par vigabatrin au long cours. Journal francais d'ophtalmologie $2009 ; 32: 83-88$.

40. Baxter PS, Gardner-Medwin D, Barwick DD, et al. Vigabatrin monotherapy in resistant neonatal seizures. Seizure. 1995;4:57-9.

41. Vauzelle-Kervroidan F, Rey E, Pons G, et al. Pharmacokinetics of the inidvidual enantiomers of vigabatrin in neonates with uncontrolled seizures. Br J Clin Pharmacol. 1996:42:779-81.

42. Pisano T, Numis AL, Heavin SB, et al. Early effective treatment of KCNQ2 encephalopathy. Epilepsia. 2015;56(5):685-91.

43. Sands $\Pi$, Balestri M, Bellini $G$, et al. Rapid and safe response to low-dose carbamazepine in neonatal epilepsy. Epilepsia. 2016 Dec;57(12):2019-30.

44. Dilena R, Striano P, Gennaro E, et al. Efficacy of sodium channel blockers in SCN2A early infantile epileptic encephalopathy. Brain and Development. 2017 Apr:39(4):345-8.

45. Baud O, Auvin S, Saliba E et al. Prise en charge thérapeutique des convulsions associées à l'accident vasculaire cérébral du nouveau-né et perspectives de neuroprotection à la phase aiguë. Arch Pediatr 2017;24(9) :9S46-9S50.

\section{Ready to submit your research? Choose BMC and benefit from:}

- fast, convenient online submission

- thorough peer review by experienced researchers in your field

- rapid publication on acceptance

- support for research data, including large and complex data types

- gold Open Access which fosters wider collaboration and increased citations

- maximum visibility for your research: over $100 \mathrm{M}$ website views per year

At $\mathrm{BMC}$, research is always in progress.

Learn more biomedcentral.com/submissions 